\title{
Chlorine Effect on Thermal Aging Behaviors of BR and CR Composites
}

\author{
Sung-Seen Choi* and Jong-Chul Kim \\ Department of Chemistry, Sejong University, Seoul 143-747, Korea. *E-mail: sschoi@sejong.ac.kr \\ Received June 21, 2010, Accepted July 28, 2010
}

\begin{abstract}
Chloroprene is a chlorine substituent of 1,3-butadiene. Butadiene rubber (BR) and chloroprene rubber (CR) composites were thermally aged at $60,70,80$, and $90^{\circ} \mathrm{C}$ for $2-185$ days in a convection oven and changes of the crosslink densities by the accelerated thermal aging were investigated. The crosslink densities increased as the aging time elapsed and as the aging temperature became higher. Degrees of the crosslink density changes of the BR composite were on the whole larger than those of the CR one except the short-term thermal aging at 60 and $70{ }^{\circ} \mathrm{C}$. The crosslink densities abnormally increased after themal aging at high temperatures for a long time. Activation energies for the crosslink density changes of the rubber composites tended to increase with increase of the aging time and the variation showed a local minimum. The activation energies of the CR composite were lower than those of the BR one. The experimental results were explained with a role of ligand of chlorine atom of CR in a zinc complex, steric hindrance by chlorine atom of $\mathrm{CR}$, and oxidation of rubber chain.
\end{abstract}

Key Words: Thermal aging, BR, CR, Crosslink density, Chlorine effect

\section{Introduction}

Butadiene rubber (BR) and chloroprene rubber (CR) have the same backbone of $\sim \mathrm{C}-\mathrm{C}=\mathrm{C}-\mathrm{C} \sim$. Chloroprene $\left(\mathrm{CH}_{2}=\mathrm{CCl}-\mathrm{CH}=\right.$ $\mathrm{CH}_{2}$ ) which is a monomer of $\mathrm{CR}$ is a chlorine substituent of 1,3-butadiene $\left(\mathrm{CH}_{2}=\mathrm{CH}-\mathrm{CH}=\mathrm{CH}_{2}\right)$ which is a monomer of $\mathrm{BR}$. The difference in the structures of BR and $\mathrm{CR}$ is only chlorine atom exchanged with hydrogen atom as shown in Scheme 1. BR is one of popular synthetic rubbers and has good physical properties but is sensitive to oil. It is widely employed in tire treads. BR has good abrasion resistance, low heat buildup, and good crack resistance. CR is used for oxidation-resistant and oil-resistant elastomers. ${ }^{1-3}$ Its application areas are cables, transmission belts, conveyor belts, moulded goods, and so on.

Crosslink type and degree of crosslink density of a rubber vulcanizate determine the physical properties such as modulus, hardness, resilience, elongation at break, heat build-up, and so forth. ${ }^{4}$ Sulfide linkages, especially polysulfides, are dissociated by heating ${ }^{5,6}$ and this brings about decrease of the crosslink density. Curatives, especially sulfur, in rubber vulcanizates make new crosslinks ${ }^{7}$ and this results in increase of the crosslink density. Crosslink density of a rubber vulcanizate is changed by thermal aging. ${ }^{8-12}$ In general, when sulfur-cured rubber vulcanizates are thermally aged, the crosslink densities increase and the degree also increases as the aging temperature and time increase. ${ }^{13-15}$ Crosslink density change by thermal aging is also one of reasons about permanent deformation of a rubber vulcanizate. $^{13-15}$

Brown and coworkers reported physical property changes of

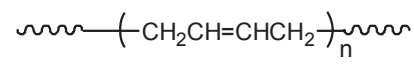

$\mathrm{BR}$

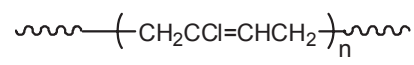

CR

Scheme 1. Chemical structures of $B R$ and $C R$ rubber composites after natural aging for 40 years and compared the results with the accelerated heat aging results. ${ }^{16,17}$ Relative deviations for the physical property changes of natural aging results were very big but the results are valuable. The big deviation of the physical property may be due to the difference in the initial states of the samples. A number of samples are needed to measure physical properties and to perform thermal aging for long time. Initial states of samples should be the same to minimize the experimental errors. States of samples obtained from one tensile specimen are the same. When samples obtained from one tensile specimen are used for an experiment, the experimental errors should be reduced. Thus, sample size should be small to minimize the experimental errors, but a relatively large sample size for measurement of the physical properties should be required. Sample dimension for measurement of the crosslink density is less than $1 \mathrm{~cm} \times 1 \mathrm{~cm}$. Hence, experimental errors for thermal aging behaviors of a rubber article can be largely reduced by measuring the crosslink density changes not the physical property changes.

In the present work, we studied thermal aging behaviors of $\mathrm{BR}$ and $\mathrm{CR}$ composites by measuring crosslink density changes to examine the chlorine effect on the thermal aging behaviors. Recently, some studies about aging properties of rubber vulcanizates including BR and CR were reported. ${ }^{18-21}$ Thermal aging was performed for 2 to 185 days in a convection oven and the thermal aging behaviors were investigated by dividing into short- and long-term agings. Activation energy for the crosslink density change by thermal aging was obtained from Arrhenius plot and the variation with the aging time was also investigated to characterize the thermal aging behaviors.

\section{Experimental}

Carbon black-reinforced BR and CR compounds were made of the following: rubber (BR or CR $100.0 \mathrm{phr}$ ), carbon black (N220 50.0 phr), antidegradants ( $N$-phenyl- $N$ '-(1,3-dimethylbutyl)- $p$-phenylenediamine (HPPD) $2.0 \mathrm{phr}$ and wax $2.0 \mathrm{phr}$ ), 
cure activators (stearic acid $2.0 \mathrm{phr}$ and $\mathrm{ZnO} 2.0 \mathrm{phr}$ ), $N$-tertbutyl-2-benzothiazole sulfenamide (TBBS, $1.4 \mathrm{phr}$ ), and sulfur (1.4 phr). BR 01 of Kumho Petrochemical Co. and Skyprene of Tosoh Co. were employed as BR and CR, respectively. Mixing was performed in a Banbury type mixer at a rotor speed of 45 and $30 \mathrm{rpm}$ for master batch (MB) and final mixing (FM) stages, respectively. The initial temperatures of the mixer were 110 and $80{ }^{\circ} \mathrm{C}$ for MB and FM stages, respectively. The MB compounds were prepared as follow: (1) the rubber was loaded into the mixer and preheated for $0.5 \mathrm{~min}$, (2) the carbon black was compounded into the rubber for $2.0 \mathrm{~min}$, (3) the antidegradants and cure activators were mixed for $2.0 \mathrm{~min}$ and the compounds were discharged. The FM compounds were prepared by mixing the sulfur and TBBS with the MB compounds for $2.0 \mathrm{~min}$. The vulcanizates were prepared by curing at $160^{\circ} \mathrm{C}$ for $20 \mathrm{~min}$ in a compression mold (140 $\mathrm{mm} \times 140 \mathrm{~mm} \times 2 \mathrm{~mm})$.

Sample dimension for the thermal aging experiment was 3 $\mathrm{cm} \times 6 \mathrm{~cm}$ (thickness $2 \mathrm{~mm}$ ). Thermal aging was performed at $60,70,80$, and $90{ }^{\circ} \mathrm{C}$ for $2-185$ days in a convection oven. Crosslink densities of the samples before and after the thermal aging were measured by swelling method. Organic additives in the samples were removed by extracting with tetrahydrofuran (THF) and $n$-hexane for 3 and 2 days, respectively, and they were dried for 2 days at room temperature. The weights of the organic materials-extracted samples were measured. They were soaked in toluene for 2 days and the weights of the swollen samples were measured. The swelling ratio $(\mathbf{Q})$ was calculated by the equation (1)

$$
\mathbf{Q}=\left(\mathbf{W}_{\mathbf{s}}-\mathbf{W}_{\mathbf{u}}\right) / \mathbf{W}_{\mathbf{u}}
$$

where $\mathbf{W}_{\mathbf{s}}$ and $\mathbf{W}_{\mathbf{u}}$ are the weights of the swollen and unswollen samples. In general, the reciprocal swelling ratio (1/Q) was used as the apparent crosslink density. Experiments with different samples were carried out three times and were then averaged. Crosslink denisty change $\left(\boldsymbol{\Delta} \mathbf{X}_{\mathbf{c}}\right)$ was calculated by the equation (2)

$$
\Delta \mathbf{X}_{\mathbf{c}}=100 \times\left\{\left(\mathbf{1} / \mathbf{Q}_{\mathbf{f}}\right)-\left(\mathbf{1} / \mathbf{Q}_{\mathbf{i}}\right)\right\} /\left(\mathbf{1} / \mathbf{Q}_{\mathbf{i}}\right)
$$

where $\left(\mathbf{1} / \mathbf{Q}_{\mathrm{i}}\right)$ and $\left(\mathbf{1} / \mathbf{Q}_{\mathrm{f}}\right)$ are the apparent crosslink densities of the specimens before and after the thermal aging.

Organic materials remaining in the aged samples were extracted with THF and analyzed with gas chromatograph/mass spectrometer (GC/MS). GC/MS chromatograms and mass spectra of the extracted materials were acquired with $6890 \mathrm{~N} /$ 5987 GC/MS of Agilent Co. DP-5MS capillary column (length $30 \mathrm{~m}$ ) of Agilent Co. was used. Injector temperature of the GC was $250{ }^{\circ} \mathrm{C}$. The GC oven temperature program was as follows: (1) the initial temperature was $70^{\circ} \mathrm{C}$ and kept for $3 \mathrm{~min}$, (2) the temperature was increased from 70 to $300{ }^{\circ} \mathrm{C}$ at a rate of $10{ }^{\circ} \mathrm{C} / \mathrm{min}$.

\section{Results and Discussion}

Diene rubbers such as natural rubber (NR), styrene-butadiene rubber (SBR), BR, and CR have unsaturated carbon-carbon double bonds $(\mathrm{C}=\mathrm{C})$ in the polymer chain backbone. Hence, they have allylic protons which are active sites to participate in sulfur crosslinking reactions. BR and CR have the same content of allylic proton, four allylic protons every repeat unit as shown in Scheme 1. The experimental results were arranged by dividing the results with short-term aging of 2 - 35 days and long-term aging after 35 days as shown in Figures 1 - 4. The crosslink densities of all the samples increased after the thermal aging. In general, increased crosslink density of a sulfur-cured rubber vulcanizate is explained with the formations of new crosslinks by curative residues such as elemental sulfur, cure accelerator residues, and zinc complexes in a rubber vulcanizate. $^{7,9,22,23}$ Especially, free sulfur remaining in a rubber vulcanizate reacts well with rubber chains and makes new crosslinks. ${ }^{7}$ Combination reactions between pendent sulfide groups terminated by an accelerator residue also enhance the crosslink density. ${ }^{9,22,23}$ Zinc complexes consisted of zinc oxide, fatty acids, cure accelerators, and sulfur activate crosslinking reactions. It also makes a cure rate faster and enhances the crosslink density. The $\Delta \mathbf{X}_{\mathbf{c}}$ s tended to increase as the aging time elapsed, however those for the short-term aging at low temperatures of 60 and $70{ }^{\circ} \mathrm{C}$ were somewhat fluctuated. The $\Delta \mathbf{X}_{\mathbf{c}}$ s notably increased as the aging temperature increased.

The $\Delta \mathbf{X}_{\mathbf{c}}$ s of the $\mathrm{CR}$ composite aged at 60 and $70{ }^{\circ} \mathrm{C}$ for short period were larger than those of the BR one as shown in Figures
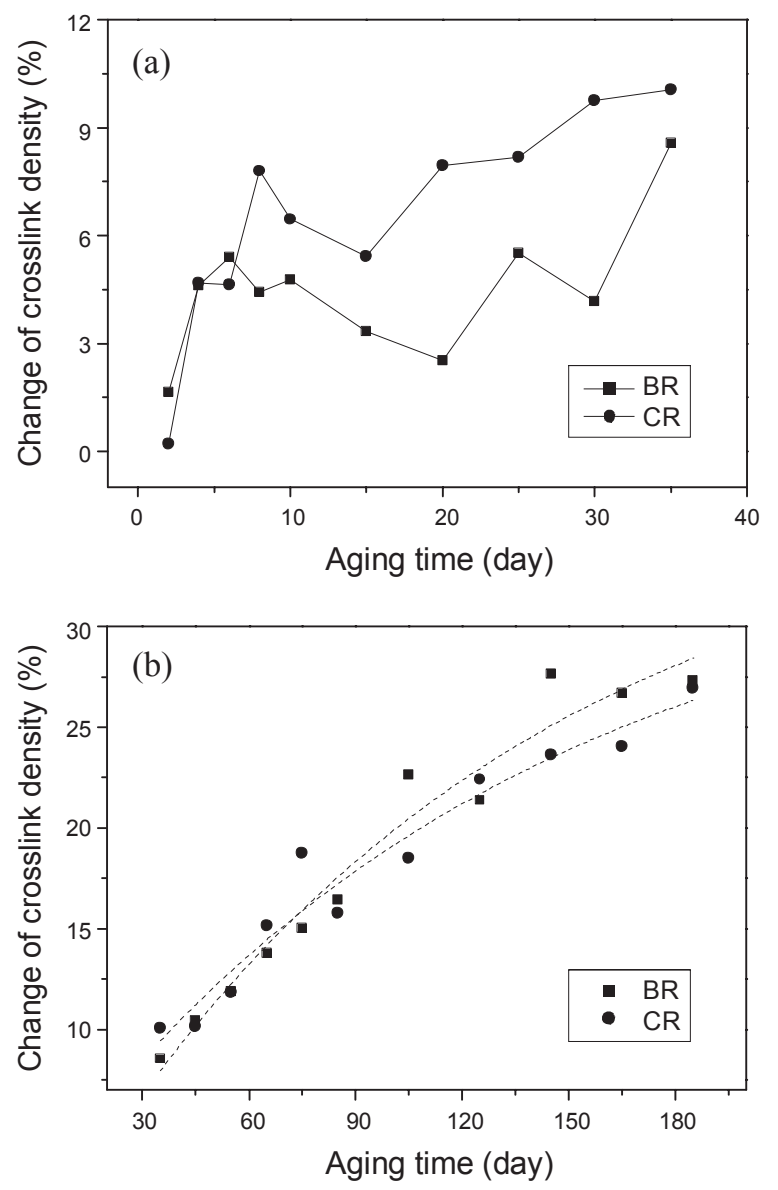

Figure 1. Variations of the crosslink density changes of the rubber composites by short-term (a) and long-term (b) thermal aging at $60^{\circ} \mathrm{C}$ with the aging time. The squares and circles indicate the BR and CR specimens, respectively. 

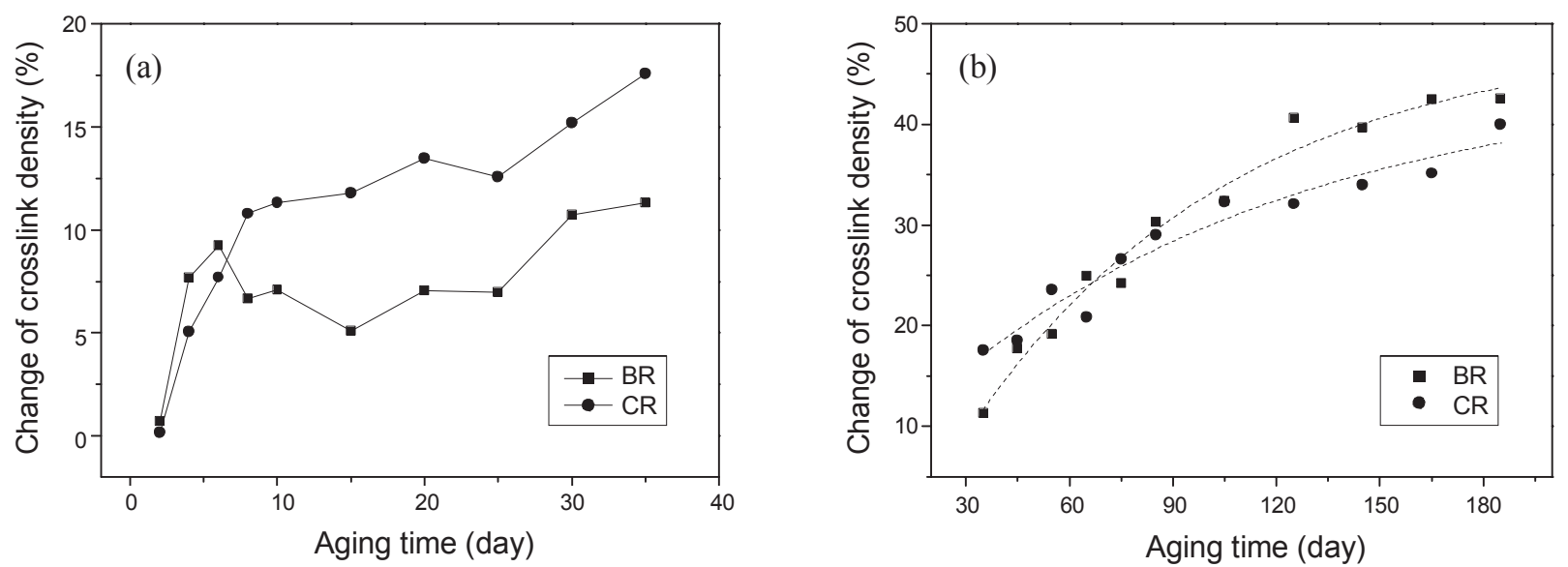

Figure 2. Variations of the crosslink density changes of the rubber composites by short-term (a) and long-term (b) thermal aging at $70{ }^{\circ} \mathrm{C}$ with the aging time. The squares and circles indicate the BR and CR specimens, respectively.
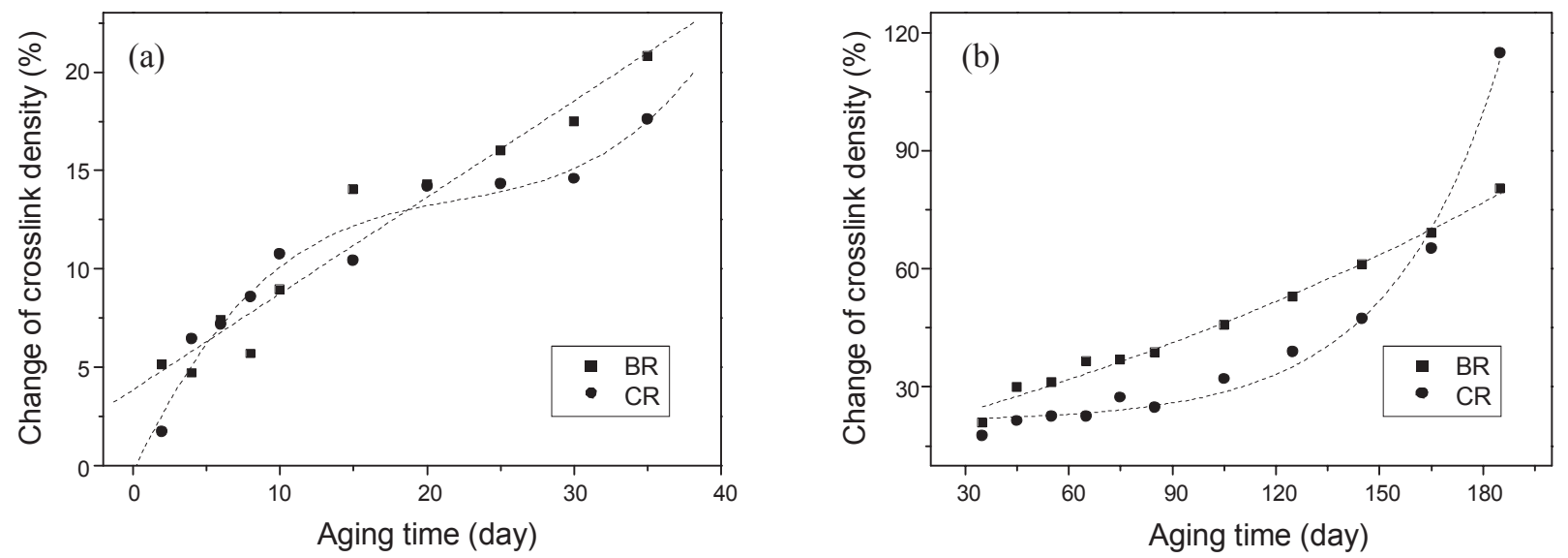

Figure 3. Variations of the crosslink density changes of the rubber composites by short-term (a) and long-term (b) thermal aging at $80{ }^{\circ} \mathrm{C}$ with the aging time. The squares and circles indicate the BR and CR specimens, respectively.
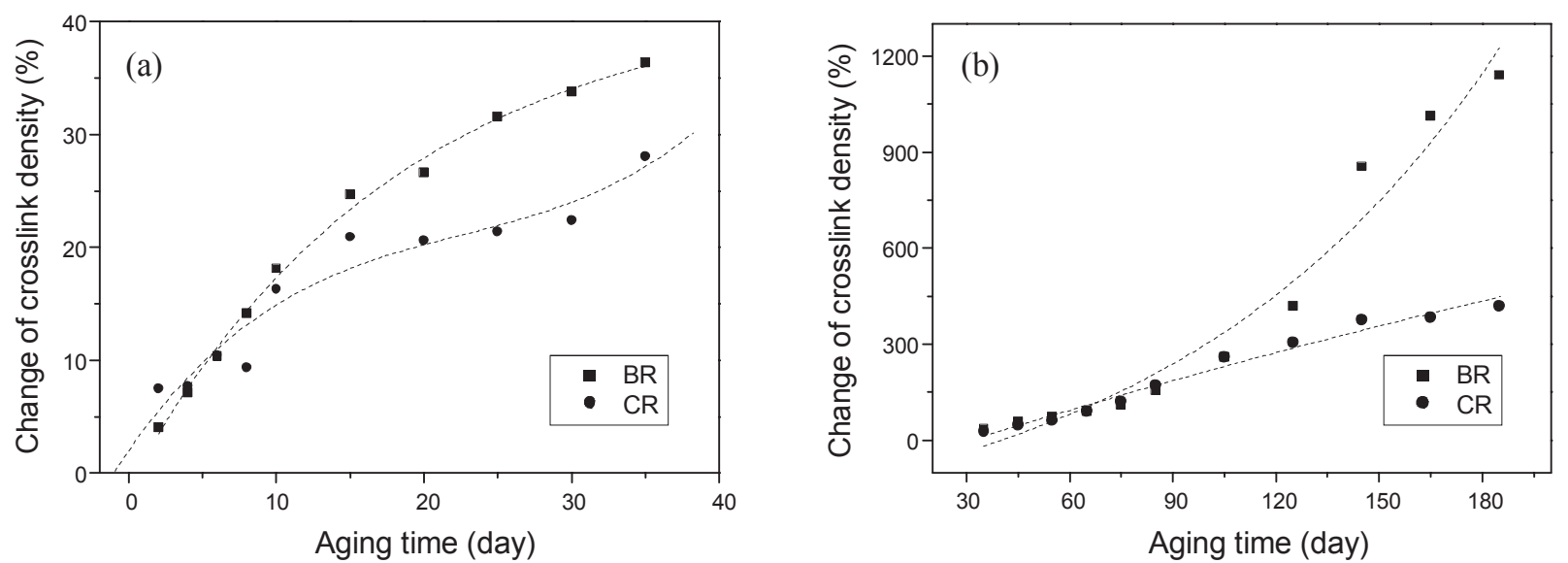

Figure 4. Variations of the crosslink density changes of the rubber composites by short-term (a) and long-term (b) thermal aging at $90^{\circ} \mathrm{C}$ with the aging time. The squares and circles indicate the BR and CR specimens, respectively.

1(a) and 2(a). This can be explained with the role of chlorine atom as a ligand in a zinc complex as shown in Scheme 2. If zinc complexes are activated by chlorine, the activation energy for crossinking reactions decreases. Thus, formation of new crosslinks will be activated. Differences in the $\Delta \mathbf{X}_{\mathbf{c}}$ s of the BR and CR composites aged at $80{ }^{\circ} \mathrm{C}$ for short period were not significant as shown in Figure 3(a). For the short-term thermal aging at $90{ }^{\circ} \mathrm{C}$, the $\Delta \mathbf{X}_{\mathbf{c}}$ s of the BR composite were larger than those of CR one as shown in Figure 4(a). This can not be explained with the role of chlorine atom as a ligand in a zinc com- 


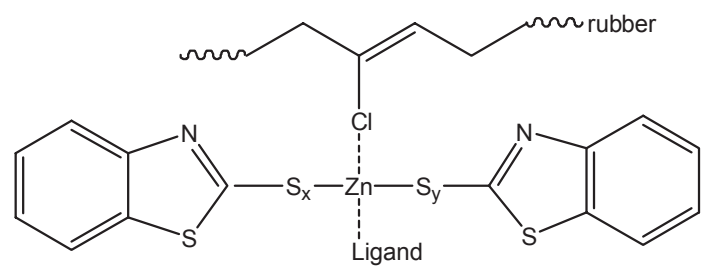

Scheme 2. Structure of zinc complex including chlorine

plex. For the long-term thermal aging at $70-90{ }^{\circ} \mathrm{C}$, the $\Delta \mathbf{X}_{\mathbf{c}}$ s of $\mathrm{BR}$ composite were on the whole larger than those of the $\mathrm{CR}$ one as shown in Figures 2 - 4. The higher $\Delta \mathbf{X}_{\mathbf{c}}$ s of the BR composite than the $\mathrm{CR}$ one can be explained with the steric hindrance for crosslinking reactions by chlorine atom and weakening of binding strength between zinc and chlorine in a zinc complex. Atomic radii of hydrogen and chlorine atoms are 37 and 100 pm, respectively. Since chlorine atom in the rubber chain of CR is neighbored around allylic protons and is relatively big, allylic protons will be hindered by chlorine atom and formation of new crosslinks will be inhibited. By increasing the temperature, rotation of chlorine atom is more activated and the steric hindrance is also more activated. Binding strength between zinc and chlorine in a zinc complex is also weakened by increasing the aging temperature. The weak binding strength between zinc and chlorine results in high activation energy for the crosslinking reactions. Thus, degree of the crosslink density increment of the CR composite by long-term thermal aging at high temperatures will be relatively smaller than that of the BR one.

The $\boldsymbol{\Delta} \mathbf{X}_{\mathbf{c}}$ s of the BR composite aged at $80{ }^{\circ} \mathrm{C}$ were on the whole larger than those of the $\mathrm{CR}$ one as shown in Figure 3. However, the $\boldsymbol{\Delta} \mathbf{X}_{\mathbf{c}}$ of the CR composite aged at $80{ }^{\circ} \mathrm{C}$ for 185 days was larger than that of the BR one. This abnormal behavior may be due to the amount of antidegradant remaining in the sample. Consumption rate of HPPD (antidegradant) in the CR composite was much faster than that of the BR one as shown in Figures 5 and 6. Initial contents of HPPD in the BR and CR samples were the same as described in the experimental section. Amount of HPPD remaining in the BR composite after thermal aging at $90{ }^{\circ} \mathrm{C}$ for 5 days was much larger than that in the $\mathrm{CR}$ one as shown in Figures 5(a) and 6(a). HPPD protects rubber chains from dissociation by oxidation. When HPPD is not sufficiently in the sample, it is possible that some rubber chains are oxidated and some new crosslinks are formed. For the long-term thermal aging at $90{ }^{\circ} \mathrm{C}$, values of the $\Delta \mathbf{X}_{\mathbf{c}}$ S were very big. Values of the $\Delta \mathbf{X}_{\mathbf{c}}$ s of both BR and CR composites aged at $90{ }^{\circ} \mathrm{C}$ for longer than 100 days were above $200 \%$ as shown in Figure 4(b). This is also due to lack of the remaining HPPD. HPPD in the BR and CR composites after thermal aging at $90{ }^{\circ} \mathrm{C}$ for 35 days was not detected as shown in Figures 5(b) and 6(b). This means that HPPD was almost exhausted by thermal aging at $90{ }^{\circ} \mathrm{C}$ for 35 days. If antidegradants do not exist in a rubber vulcanizate, rubber chains are degraded by oxidation and then new chemical bonds between rubber chains can be formed by a radical process. A direct bond formation between rubber chains results in increase of the crosslink density. For the long-term thermal aging at $90{ }^{\circ} \mathrm{C}$, the $\Delta \mathbf{X}_{\mathbf{c}} \mathrm{s}$ of the BR composite were much larger than those of the CR one after 105 days. Values of the

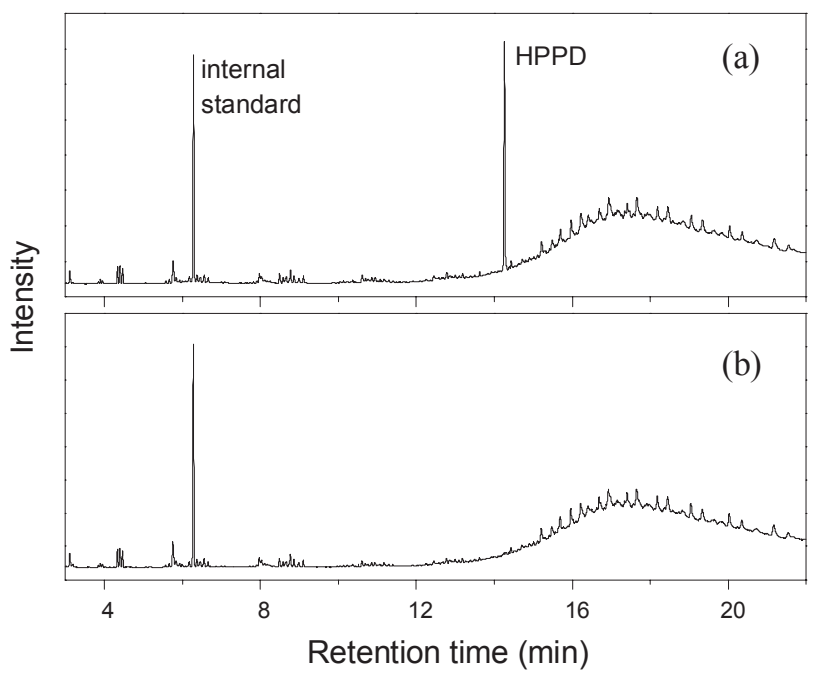

Figure 5. GC/MS TIC chromatograms of the organic materials extracted with THF from the BR composite aged at $90{ }^{\circ} \mathrm{C}$ for 5 (a) and 35 (b) days.

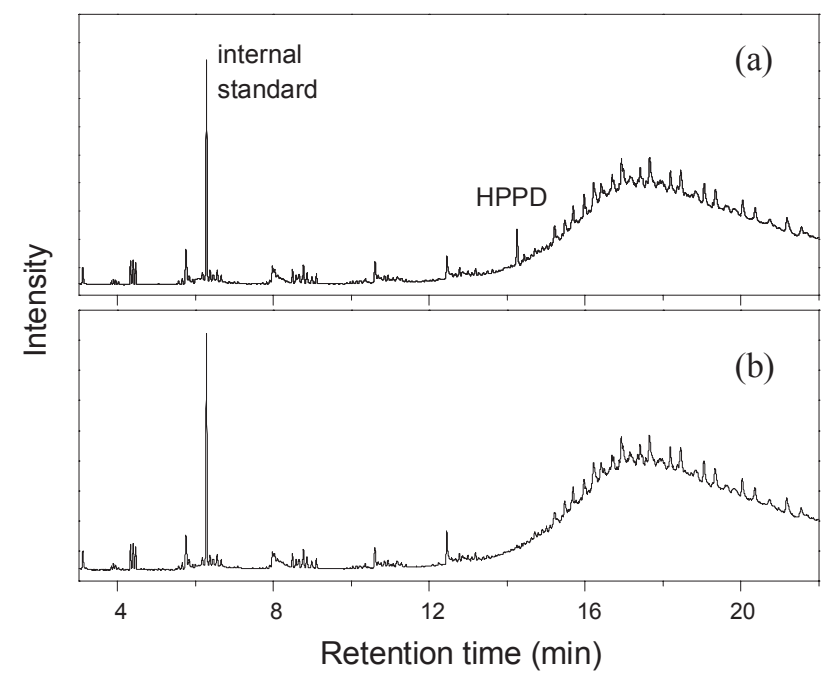

Figure 6. GC/MS total ion current (TIC) chromatograms of the organic materials extracted with THF from the CR composite aged at $90{ }^{\circ} \mathrm{C}$ for 5 (a) and 35 (b) days.

$\Delta \mathbf{X}_{\mathrm{c}}$ s of the BR composite aged at $90{ }^{\circ} \mathrm{C}$ for longer than 140 days were even larger than $500 \%$. This may be due to the difference in the reaction rates of oxgen or ozone with the rubber chain. The reaction rate of ozone with $\mathrm{BR}$ is faster than that of CR. Rate constants for the reactions of BR and CR with ozone are 0.6 and $0.4 \mathrm{~g} / \mathrm{mol} \cdot \mathrm{s}$, respectively. ${ }^{24}$ Hence, degree of the direct $\mathrm{C}-\mathrm{C}$ bond formation between rubber chains by oxidation for $\mathrm{BR}$ will be larger than that of CR when antidegradants in the sample were exhausted.

Activation energies for the $\boldsymbol{\Delta} \mathbf{X}_{\mathbf{c}} \mathbf{s}$ by thermal aging were obtained from the Arrhenius plot of $\ln k v_{s} 1 / T$, where $k$ is the $\Delta \mathbf{X}_{\mathbf{c}}$ and $T$ is the aging temperature, in order to compare the thermal aging behaviors of the $\mathrm{BR}$ and $\mathrm{CR}$ composites. The activation energies varied with the aging time as shown in Figure 7. This implies that states of the samples depend on the aging time. Density and type of crosslinks are changed hourly because new 


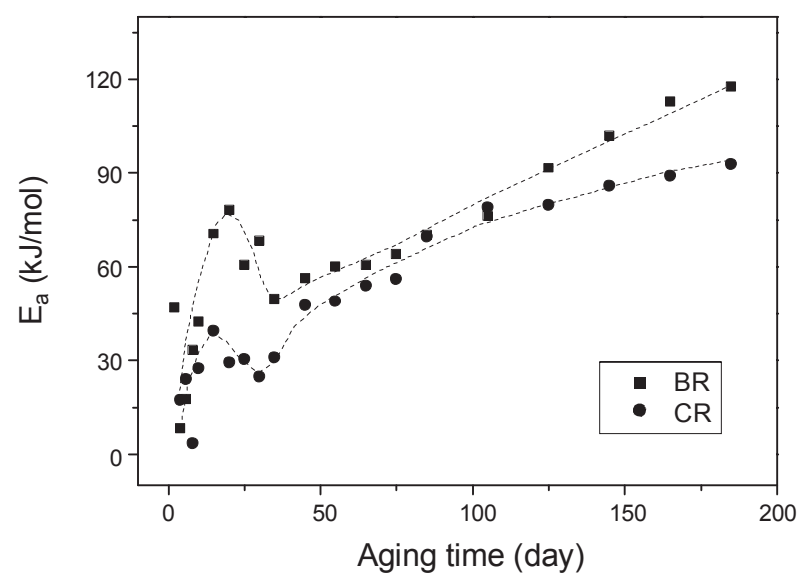

Figure 7. Variations of the activation energies for the crosslink density changes by thermal aging as a function of the aging time. The squares and circles indicate the BR and CR specimens, respectively.

crosslinks are formed and the existing crosslinks are dissociated by thermal aging. Furthermore, the kinds and amounts of curative residues remaining in the sample may be also changed every moment. Crosslinking-related chemicals include zinc complexes, curative residues, sulfur, and so on. The activation energy curves showed one maximum and one minimum points. At the initial period of aging, remaining crosslinking-related chemicals can gather and participate in crosslinking reactions. This may make the activation energy decrease. The increased activation energy after the minimum point may be because consumption of the crosslinking-related chemicals overcomes gathering of the existing crosslinking-related chemicals and formation of the new crosslinking-related chemicals. The activation energies of the $\mathrm{CR}$ composite were lower than those of the BR one. This may be due to the role of chlorine atom as a ligand in a zinc complex. Activation of zinc complexes in CR by chlorine reduces the activation energy of vulcanization.

\section{Conclusions}

The crosslink densities of BR and CR composites were increased by thermal aging. Due to the role of ligand of chlorine atom of $\mathrm{CR}$ in a zinc complex, for the short-term thermal aging at low temperatures, the crosslink density changes of the CR composite were larger than those of the BR one. However, for the short-term thermal aging at high temperatures and the long- term thermal aging, the crosslink density changes of the BR composite were larger than those of the $\mathrm{CR}$ one because of steric hindrance for the crosslinking reactions by chlorine atome in CR and weakening of binding strength between zinc and chlorine in a zinc complex. For long-term thermal aging at high temperatures, the crosslink density abnormally increased because of lack of antidegradants. The activation energies for crosslink density change of CR composite were lower than those of BR one because of the role of ligand of chlorine atom in a zinc complex.

Acknowledgments. This research was supported by a grant from the Fundamental R\&D Program for Core Technology of Materials funded by the Ministry of Knowledge Economy, Republic of Korea.

\section{References}

1. Johnson, P. R. Rubber Chem. Technol. 1976, 49, 650.

2. Hwang, B. K.; Hong, K. H.; Park, H. Y.; Jeon, I. R.; Seo, K. H. Elast. Comps. 2009, 44, 299

3. Choi, S.-S. J. Appl. Polym. Sci. 2002, 83, 2609.

4. Morrison, N. J.; Porter, M. Rubber Chem. Technol. 1984, 57, 63.

5. Chen, C. H.; Koenig, J. L.; Shelton, J. R.; Collins, E. A. Rubber Chem. Technol. 1981, 54, 734.

6. Choi, S.-S. Kor. Polym. J. 1997, 5, 39.

7. Layer, R. W. Rubber Chem. Technol. 1992, 65, 211.

8. Choi, S.-S. Elast. Comps. 2009, 44, 116.

9. Choi, S.-S.; Jang, J.-H. Elast. Comps. 2009, 44, 442.

10. Choi, S.-S. Polym. Int. 2001, 50, 107.

11. Choi, S.-S.; Han, D.-H.; Ko, S.-W.; Lee, H. S. Bull. Kor. Chem. Soc. 2005, 26, 1853.

12. Choi, S.-S.; Ha, S.-H.; Woo, C.-S. Bull. Kor. Chem. Soc. 2006, 27, 429.

13. Choi, S.-S.; Han, D.-H. J. Appl. Polym. Sci. 2008, 110, 3560.

14. Choi, S.-S.; Han, D.-H. Thermochim. Acta 2009, 490, 8.

15. Choi, S.-S.; Han, D.-H. J. Appl. Polym. Sci. 2009, 114, 935.

16. Brown, R. P.; Butler, T. Natural Ageing of Rubber. Changes in Physical Properties over 40 Years; RAPRA Technology Ltd.: 2000.

17. Brown, R. P.; Butler, T.; Hawley, S. W. Ageing of Rubber. Accelerated Heat Ageing Test Results; RAPRA Technology Ltd.: 2001.

18. Jang, J.-H.; Choi, S.-S. Elast. Comps. 2009, 44, 442.

19. Ahn, W. S.; Park, K.-H. Elast. Comps. 2009, 44, 269.

20. Choi, S.-S. Elast. Comps. 2009, 44, 116.

21. Sae-oui, P.; Sirisinha, C.; Thepsuwan, U.; Hatthapanit, K. Eur. Polym. J. 2007, 43, 185.

22. Gradwell, M. H. S.; McGill, W. J. J. Appl. Polym. Sci. 1996, 61, 1131.

23. Gradwell, M. H. S.; McGill, W. J. J. Appl. Polym. Sci. 1996, 61, 1515.

24. Layer, R. W.; Lattimer, R. P. Rubber Chem. Technol. 1990, 63, 426. 